\title{
LAS INSUFICIENCIAS DEL RELATIVISMO RADICAL Y EL POTENCIAL DEL RELATIVISAMO MODERADO
}

\author{
H.C.F. Mansilla \\ Real Academia Española \\ Academia de Ciencias de Bolivia \\ Academia Boliviana de la Lengua
}

http://dx.doi.org/10.5209/NOMA.54645

\begin{abstract}
Resumen.- Este ensayo analiza las carencias de los enfoques relativistas radicales y los aspectos positivos que contienen las teorías relativistas moderadas, sobre todo en lo referido a la confrontación entre principios universalistas y particularistas en la construcción de identidades colectivas. Por un lado tenemos los principios universalistas, basados en el racionalismo del siglo XVIII, que son percibidos en el Tercer Mundo como una tendencia niveladora. Por otro lado tenemos los principios particularistas, basadas en el relativismo, que buscan comprender los casos particulares mediante un impulso reconstructivo. Mediante una crítica de ambas corrientes el autor cree posible una síntesis fructífera de ambos principios, considerados como complementarios. Por ejemplo la ética universalista y los derechos humanos pueden conformar los cimientos para un derecho efectivo a la diferencia.
\end{abstract}

Palabras clave: derechos humanos, Giambattista Vico, Hans-Georg Gadamer, hermenéutica, Jürgen Habermas, relativismo

\section{The Incompetences of Radical Relativism and the Potential of Moderate Relativism}

Abstract.- This essay deals with the deficiencies of the radical relativist approaches and the positive aspects of moderate relativist theories, especially with regard to the confrontation of both during the building ofcollective identities. On the one side we have the universalistic principles, based on 18th century rationalism, which are perceived in the Third World as a leveling tendency. Particularistic currents are based on relativism. They seek to understand each case by reconstructing its history. Making a critique of both tendencies, the author attempts at a prolific synthesis of them, which are considered as complementary. For instance universal ethics and human rights could build the fundamentals for an effective right to difference.

Key words: Giambattista Vico, Hans-Georg Gadamer, hermeneutics, human rights, Jürgen Habermas, relativism

\section{Preliminares}

Jürgen Habermas afirmó que en los fragmentos y discontinuidades, en lo marginal e inesperado se hallan a veces elementos valiosos que permiten entender mejor el proceso emancipatorio de la humanidad'.Siguiendo esta línea, aquí intentaré un enfoque lateral, es

\footnotetext{
1 Jürgen Habermas, Politik, Kunst, Religion. Essays über zeitgenösissche Philosophen (Politica, arte, religión. Ensayos en torno a filósofos contemporáneos), Stuttgart: Reclam 1978, p. 6.
} 
decir: desacostumbrado, con respecto a la crítica de las posiciones relativistas, que hoy son predominantes en los ambientes intelectuales de casi todo el mundo. El mérito y el potencial teóricos del relativismo moderado residen enla crítica de las leyes generales de la evolución histórica y en el cuestionamiento de los valores de pretensión universal. Esta posición trae consigo una visión diferente, una nueva estimación positiva de lo particular, específico y concreto o, como decía Theodor W. Adorno, de lo no-idéntico, de lo que no se deja integrar fácilmente en las grandes categorías de índole universalista ${ }^{2}$. El programa de Adorno apuntaba al rescate de aquello que no puede o debe estar subordinado bajo los imperativos de lo general-abstracto. Pero Adorno no fue un relativista (según los términos actuales), aunque hay notables paralelismos entre su pensamiento y las concepciones postmodernistas del presente. Él supuso que algunas reglas generales del pensamiento son indispensables, por ejemplo para no caer en crasas contradicciones o en incongruencias sutiles. La metafísica debería ser salvada como ciencia de la diferenciación, es decir: como un instrumento que garantice un mínimo de lógica ${ }^{3}$. El rechazo doctrinario de la lógica y la metafísica, que parece un postulado tan necesario, simpático y hasta juvenil, tan acorde con nuestros tiempos ligeros, puede significar también la eliminación de los fundamentos de la moral y de todo juicio valorativo referido a los terrenos de la literatura, las artes $y$, en el fondo, de la convivencia humana.

De todas maneras: la poca popularidad actual de temáticas como la ética en general ${ }^{4}$, la verdad en asuntos públicos y la decadencia de la estética tiene que ver con la pérdida de una dimensión de entendimiento de índole más o menos universalista, con el descrédito de la veracidad en casi todos las relaciones comunicacionales y con las dificultades de implementar una praxis política que antiguamente se denominaba racional ${ }^{5}$. Hoy se da, evidentemente, una interesante

2 Cf. el brillante texto de Gerhard Schweppenhäuser, Theodor W. Adorno zur Einführung (Introducción a Theodor W. Adorno), Hamburgo: Junius 2013, pp. 52-53, 6365.

3lbid., pp. 53-54, 66-68.

${ }_{4}^{4}$ ürgen Habermas dice, siguiendo a Theodor W. Adorno, que la ética es ahora una "ciencia triste", que a lo sumo se puede expresar en aforismos: Jürgen Habermas, Begründete Enthaltsamkeit. Gibtespostmetaphysische Antworten auf die Frage nach dem "richtigen Leben"? (Abstinencia fundamentada. ¿Hay respuestas postmetafísicas a la pregunta sobre la "vida correcta"?), en: Jürgen Habermas, Die Zukunft der menschlichen Natur. Aufdem Weg zu einerliberalen Eugenik? (El futuro de la naturaleza humana. ¿En camino a una eugenesia liberal?), Frankfurt: Suhrkamp 2005, pp. 11-33, aquí p. 11.

5 Sobre la difusión contemporánea de identidades autónomas, que conlleva una pluralización de concepciones de justicia y del bien común, cercana a la dilución y evaporación de los mismos, cf. Axel Honneth, Organisierte Selbstverwirklichung. Paradoxien der Individualisierung (La autorrealización organizada. Paradojas de la individualización), en: Axel Honneth, Das Ich im Wir. Studienzur Anerkennungstheorie (EI 
"reflexión permanente" 6 , que nace de la consciencia del carácter totalmente contingente de todo desarrollo histórico, y de la dificultad de vincular razonablemente ese carácter con las pretensiones universalistas y racionalistas de las ciencias sociales. De ahí se derivan rápidamente una crítica radical del valor perenne de las teorías clásicas y la ya conocida tesis de la dependencia sustancial de todo autor con respecto a su contexto local de origen y experiencia ${ }^{7}$. Pese a la epistemología heurística y a aspectos fructíferos que exhiben estas tendencias relativistas, hay que señalar que las mismas se adentran de tal manera en los contextos estudiados que pierden todo nexo claro con nuestros intereses y temas contemporáneos.

La hermenéutica y el postmodernismo han cuestionado radicalmente el racionalismo occidental y sus pretensiones. Hay que tomar en cuenta que pensadores y escuelas asociadas a la cultura occidental se enfrentaron también a las tradiciones, a todo aquello que, por muy ancestral y sagrado que pareciera ser, sólo conllevaba servidumbre y vínculos irracionales. Y es probable que algunos rasgos de todo orden social premoderno hayan pertenecido y pertenezcan al ámbito de lo irracional, lo artificialmente arcaico y lo políticamente autoritario, es decir a la esfera de lo indefendible. Por ello es que el relativismo axiológico del postmodernismo ha resultado ser tan popular en todo el Tercer Mundo: los rasgos autoritarios de sus tradiciones y también de sus prácticas contemporáneas aparecen, por ejemplo, como formas aceptables de una identidad colectiva que no puede ser analizadas desde afuera. Por todos estos motivos hay que echar un vistazo a las versiones tempranas y muy brillantes de crítica a las pretensiones universalistas del racionalismo, porque resulta interesante acercarse a las incertidumbres de la razón como la mejor forma de defenderla ${ }^{8}$.

\section{Vico y Herder en la visión de Isaiah Berlin}

yo en el nosotros. Estudios en la teoría del reconocimiento), Berlín: Suhrkamp 2010, pp. 202-221, especialmente p. 202, 210.

${ }^{6}$ Axel Honneth, Geschichtsschreibung als Befreiung. Quentin Skinners Revolutionierung der Ideengeschichte (La escritura de la historia como liberación. La revolución de la historia de las ideas por Quentin Skinner), en: Axel Honneth, Vivisektionen eines Zeitalters. Porträts zur Ideengeshichte des 20. Jahrhunderts (Vivisecciones de una época. Retratos en torno a la historia de las ideas del siglo XX), Berlín: Suhrkamp 2014 , pp. 263-280, aquí pp. 263-264.

7lbid., pp. 264-271, 274.

8 Tesis de Carlos Pereda, Zwei Modelle auf geklärter (Dos modelos de razón ilustrada), en: Christoph Menke / Martin Seel (comps.), Zur Verteidigung der Vernunftgegen ihre Liebhaberund Verächter (Una defensa de la razón contra sus amantes y despreciadores), Frankfurt: Suhrkamp 1993, pp. 129-148, aquí p. 130. 
Un notable y temprano crítico del racionalismo fue el italiano Giambattista Vico(1668-1744)9, cuya obra principal, la Nueva ciencia sobre la naturaleza común de las naciones(primera edición en 1725), postuló expresamente la separación entre las disciplinas del espíritu y las ciencias naturales y se opuso a la racionalización de todos los ámbitos de la vida humana, que Vico, de manera clarividente, la asoció con una probable matematización y cuantificación de la esfera social, cultural e histórica ${ }^{10}$.El Hombre, dice Vico, no puede penetrar del todo en aquello que él no ha creado - la naturaleza -, sino aproximarse; las ciencias naturales producen sólo un conocimiento probabilístico. Podemos conocer mejor lo que hemos creado y hacemos cada día: los asuntos tratados por las ciencias espirituales, sociales e históricas. La historia, por ejemplo, no tiene la precisión de la geometría, pero podemos entender mejor sus temas. Según este pensador, comprender un proceso histórico requiere de un impulso intuitivo, identificatorio y creativo de parte del sujeto cognoscente. Este esfuerzo empático representa una certidumbre comparable a la ganada por métodos empíricos y constituye un procedimiento tan respetable y seguro como el de las ciencias naturales y exactas, aunque no esté basado, como estas, en una actividad absolutamente objetiva ${ }^{11}$. Ya que el Hombre produce la historia - en contraposición a los fenómenos naturales creados por Dios, cuya aprehensión es más problemática -, su intelecto la puede comprender adecuadamente si se adentra en ella y la reconstruye teóricamente ${ }^{2}$. Según Vico, el método cartesiano de la duda sistemática no es aplicable a fenómenos que dependen del contexto de la comunicación intersubjetiva, del marco lingüístico, de testimonios históricos aceptados como ciertos por una comunidad y del sentido común que una sociedad se otorga a sí misma ${ }^{13}$.

Por otra parte, los enfoques universalistas y armonicistas, que subordinan todo esfuerzo a una sola meta o a una concepción única de verdad y justicia - como los derivados del marxismo -, son poco propensos a permitir visiones y actitudes pluralistas y a reconocer el valor intrínseco de ellas mismas. Para Vico cada periodo histórico se halla en igual distancia con respecto a Dios: es decir que cada época posee una dignidad propia equivalente a cualquier otro tiempo histórico. Esto significa que

9 Sobre este pensador cf. Karl Vorländer, Philosophie der Neuzeit. Die Aufklärung (Filosofía de la era moderna. La llustración), vol. V de: Geschichte der Philosophie mit Quellentexten (Historia de la filosofía con textos de las fuentes), Reinbek: Rowohlt 1967, pp. 101-106; Ernst von Aster, Geschichte der Philosophie (Historia de la filosofía), Stuttgart: Kröner 1963, pp. 206-208.

10 Giambattista Vico, Die neve Wissenschaft über die gemeinschaftliche Natur der Völker (La nueva ciencia sobre el origen común de los pueblos) [1744], Reinbek: Rowohlt 1966, pp. 51-52.

${ }^{\prime \prime l}$ bid., pp. 26-29.

12 Ibid., pp. 55-62.

13 Ibid., p. 76. 
cada etapa elabora sus propios conceptos de justicia y libertad, dependientes, al menos parcialmente, del imaginario colectivo de la época. Estos ideales no son mejores o peores que los de otras culturas o de tiempos posteriores, sino diferentes. En cuanto creaciones humanas, todos los modelos culturales pueden ser reconstruidos por los investigadores que pertenecen a otros ámbitos civilizatorios, ya que estos modelos no poseen la impenetrabilidad de la naturaleza extra-humana. En este contexto podríamos considerar a los mitos como verdaderos porque expresan necesidades y anhelos de los pueblos: son la sabiduría poética de los mismos ${ }^{14}$.

No hay duda de que Vico es uno de los padres del pluralismo cultural moderno, como lo ha calificado Isaiah Berlin15. Según esta concepción, cada cultura posee sistemas inconfundibles de valores, que, pese a estar encubiertos por otros factores en el transcurso de la historia, nunca llegan a desaparecer del todo, lo que permite precisamente que generaciones posteriores los puedan reconstruir y comprender. La teoría de Vico tiene la ventaja de no caer en un relativismo extremo, ya que la facultad de entender y apreciar una cultura pretérita 0 ajena presupone una cierta unidad de las facultades cognoscitivas y valorativas de toda la humanidad. Este entendimiento imaginativo nos permite una estimación más adecuada de los ritos, las cosmologías, las metáforas, la literatura y los mitos de sociedades muy alejadas de la nuestra: adentrándose en estas creaciones humanas, no sólo podemos describir exteriormente cómo estas funcionan - lo que hacen habitualmente las ciencias naturales -, sino que podemos penetrar en las motivaciones primeras o últimas de sus autores y percatarnos que no se trata de productos de la barbarie "primitiva", del infantilismo histórico o de perturbaciones insignificantes debidas a artistas excéntricos, sino de elaboraciones humanas que bien pueden ser las nuestras ${ }^{16}$.

Vico propuso, basado en una idea aristotélica, una concepción del saber en cuanto la consciencia cumulativa de la experiencia humana: el Hombre llega a comprender su propio mundo y su presente si intuye adecuadamente las esperanzas, los temores y los anhelos que subyacen a las obras del pasado y de otros pueblos ${ }^{17}$. Ya que sus motivaciones actuales están entretejidas inseparablemente con las de

\footnotetext{
14Sobre Vico cf. los brillantes ensayos: Isaiah Berlin, The Divorce between the Sciences and the Humanities, en: Isaiah Berlin, Against the Current. Essays in the History of Ideas, Londres: Hogarth 1980, pp. 80-110; Isaiah Berlin, Vico's Concept of Knowledge, en: ibid., pp. $111-$ 119; Berlin, Vico and the Ideal of Enlightenment, en: ibid., pp. 120-129.

15Isaiah Berlin, Giambattista Vico und die Kulturgeschichte (Vico y la historia de la cultura), en: Isaiah Berlin, Das krumme Holz der Humanität. Kapitel der Ideengeschichte (La madera torcida de la humanidad. Capítulos de la historia de las ideas), Frankfurt: Fischer 1992, pp. 72-96.

16Giambattista Vico,op. cit. (nota 10), 214-223.

17lbid., pp. 100-102.
} 
sus antecesores y las de los otros, los seres humanossólo podrán conformar una sociedad digna de este nombre si logran entender y apreciar lo pretérito y lo Otro. Esta comprensión, que tiene fuertes rasgos hermenéuticos y que es usual en las ciencias histórico-sociales, es, sin duda, diferente de la explicación analítica de causas y efectos que prevalece en las ciencias naturales. Al penetrar en las culturas ajenas, nos damos cuenta de sus diferencias fundamentales y del pluralismo axiológico, que es una de las características del mundo humano, pero esta misma operación presupone la ya mencionada unidad de aptitudes cognoscitivas entre todos los hombres 18 .Los principios normativos de los "otros" son de igual manera auténticos, aunque muchas veces se manifiesten como contrarios y excluyentes. Pero aun cuando no exista una concordancia última entre ellos, podemos darnos cuenta de sus fundamentos y su razón de ser y podemos, por lo tanto, comprender su función específica en el interior de su sociedad respectiva.

Esta crítica al racionalismo clásico es importante por su calidad intrínseca y por su fecha temprana. Se refiere, además, a los problemas que la filosofía y las ciencias sociales discuten hoy en torno a la valoración de los modelos civilizatorios. En este contexto es útil examinar una posición que puede generar extremos insostenibles. Numerosos pensadores postmodernistas defienden a ultranza los particularismos y relativismos socio-culturales porque estos serían los resultados únicos de un contexto histórico también insustituible, original par excellence $y$, por lo tanto inconmensurable según cualquier parámetro de comparación histórica o sociológica. Esta concepción, que se remonta, a través de diversos canales, a Johann Gottfried Herder (1744-1803)19, rechaza todo juicio evaluativo acerca de los conjuntos socio-culturales y las etapas civilizatorias a causa de la unicidad, peculiaridad y singularidad de estos fenómenos. No se puede negar lo razonable de algunos elementos de esta doctrina, ya que las ideologías universalistas radicales - como el hegelianismo y el marxismo - se han consagrado largamente a vituperar las más diversas y nobles construcciones culturales e históricas del Hombre como meros estadios superados por el progreso y dignas, por ende, de desaparecer y ser integradas sin más dentro de las culturas y las naciones triunfantes ${ }^{20}$. La autonomía y el abanico de posibilidades de desarrollo de

\footnotetext{
18 Cf. Isaiah Berlin, Der angebliche Relativismus des europäischen Denkens im 18. Jahrhundert (El presunto relativismo del pensamiento europeo en el siglo XVIII), en: IsaiahBerlin, Das krumme..., op. cit. (nota 15), pp. 97-122, aquí p. 103, 108.

19 Sobre Herder cf. Karl Vorländer, op. cit. (nota 9), pp. 113-116; Ernst von Aster, op. cit. (nota 9), pp. 293-297.

20 No es superfluo recordar que Karl Marx acariciaba acendrados prejuicios étnicoculturales, que hoy, en el siglo XXI, son inaceptables. El gran maestro cultivaba un genuino desprecio por los eslavos y su cultura. En muchos conflictos del siglo XIX, en los cuales se enfrentaron pueblos eslavos contra poblaciones germánicas - como ocurrió en Europa oriental con respecto a los intentos de liberación étnico-cultural contra los sistemas reaccionarios de Prusia y Austria -, Marx creyó ver la lucha de la barbarie contra la civilización, del atraso contra la estabilidad y la civilización. Y en interés del
} 
cada pueblo se debían, según el joven Herder, a que cada cultura es autorreferencial y a que no existe una gradación progresiva universal de las mismas que permitiese la edificación de un continuum que vaya del atraso al progreso y que sea, por consiguiente, el criterio para juzgar la calidad evolutiva de cada cultura ${ }^{21}$. Los postmodernistas se olvidan, sin embargo, de que el Herder maduro combinó esta concepción con la idea de una humanidad universal que englobara a todos los hombres y cuya normatividad racionalista fuese al mismo tiempo la meta de la naturaleza humana22.

\section{La crítica del relativismo y particularismo}

La revalorización de los particularismos nacionales está asociada al romanticismo del siglo XIX y a doctrinas conservadoras y hasta irracionalistas. Los románticos afirmaron que las grandes corrientes homogeneizadoras han aplastado la heterogeneidad de los pueblos y el pluralismo civilizatorio, destruyendo así el carácter de hogar familiar que habían tenido previamente las comunidades políticas desaparecidas. De acuerdo a Axel Honneth, uno de los méritos principales del romanticismo consistió en descubrir el valor ético de la pertenencia cultural de cada individuo y grupo, lo que conformaría un adecuado polo contrario al frío "racionalismo monista" de la llustración clásica ${ }^{23}$.Lo romántico era también un renacimiento de los sentimientos frente al cálculo utilitario, una regeneración de las tradiciones nacionales y locales, independientemente de que estas fueran irracionales y antidemocráticas. Era una comprensible propensión anticosmopolita, en una época en que el racionalismo francés - apoyado por los ejércitos napoleónicos pretendía imponer al mundo una sola forma de organización política y cultural. La era histórica que se inicia con la Revolución Francesa y la industrialización ha sido considerada no sólo como el advenimiento del reino de la razón y la democracia, sino también como el tiempo de la

progreso y la cultura y de la "correcta" evolución histórica, como él entendía estos procesos, Marx pensó explícitamente que se podría permitir la aniquilación [sic] de los pueblos que representaban la barbarie. Cf. Karl Marx, Die revolutionäre Bewegung (EI movimiento revolucionario) [artículo de prensa del 1 de enero de 1849], en: Karl Marx I Friedrich Engels, Werke (Obras) [MEW], Berlin (RDA): Dietz 1956-1970, vol. 6, pp. 149-150; Karl Marx, Der magyarische Kamp (La lucha húngara), [artículo de prensa del 13 de enero de 1849], en: MEW, ibid., pp. 170-176; Karl Marx, Der demokratische Panslawismus (El paneslavismo democrático), [artículo de prensa del 16 de febrero de 1849], en: MEW,ibid., pp. 280-286.- Sobre este punto cf. Rolf Hosfeld, Karl Marx, Reinbek: Rowohlt 2011, pp. 70-73.

21 Johann Gottfried Herder, Ideas para una filosofía de la historia de la humanidad [1784-1791], Buenos Aires: Losada 1959, segunda parte, séptimo libro, acápite I.

22Para una visión equilibrada de Herder cf. Isaiah Berlin, The Divorce..., op. cit. (nota 14), pp. 101-103.

23 Cf. la notable obra de Axel Honneth, Das Andere der Gerechtigkeit. Aufsätze zur praktische Philosophie (Lo otro de la justicia. Ensayos sobre filosofía práctica), Frankfurt: Suhrkamp 2000, p. 311. 
deshumanización masiva, signado sobre todo por la predominancia de la racionalidad instrumental, el principio de rendimiento y eficacia y la omnipotencia del dinero en cuanto criterio universal y universalizador. Según Honneth, pensadores de muy diversas tendencias, como Theodor W. Adorno y Michel Foucault, creyeron ver a partir de 1800 una era histórica insoportable, en la cual la ideología humanista, los nuevos códigos jurídicos y el impulso uniformador de la llustración encubrían un saber instrumental que servía, sobre todo, a la consolidación del poder político24.

Las versiones del postmodernismo contemporáneo, que carecen del humanismo y del sentido de las proporciones de Herder y sobre todo de Vico, se limitan a celebrar sin más el culto de lo existente en un momento dado, terminando casi inexorablemente en alabar tanto los aspectos rescatables como los censurables de una cultura dada. La apología de lo fáctico y lo casual, de lo que se ha desplegado históricamente así y no de otra manera, desemboca a menudo en el encomio de los "prejuicios útiles"(Joseph de Maistre), tan caros a los gobernantes 25 . Este culto de lo contingente y lo dispar resulta ser también algo primordialmente conservador. Siguiendo este lineamiento, muchos pensadores afiliados al postmodernismo otorgan su aquiescencia a formas odiosas de opresión y vulneración de los derechos humanos, empleando el argumento de respetar escrupulosamente los valores nacionales y las tradiciones extraeuropeas y de combatir la asimilación forzada de estas a los cánones del "imperialismo" inmerso en la llustración y la razón de Occidente. "Nacido del combate en favor de la emancipación de los pueblos, el relativismo desemboca en el elogio de la servidumbre" 26 . Puesto que cada manifestación cultural vale lo mismo que cualquier otra, se llega a trivializar todas ellas. Esta postura trae consigo el fomento indirecto, pero efectivo de una nueva barbarie, la promoción de un infantilismo civilizatorio y el rechazo de algunas conquistas nada desdeñables como el espíritu crítico, la duda y la ironía.

Ante esta situación no es arbitraria la idea de proteger a la gente contra los abusos, daños y absurdos que eventualmente proceden de su propia tradición socio-cultural. Los fenómenos socio-políticos de la segunda mitad del siglo XX parecen mostrarnos que no hay duda de que el cosmopolitismo liberal a ultranza es vacío y que no logra concitar emociones sociales relevantes; la gente no puede desplegar plenamente sus facultades si no está enraizada en una tradición cultural viviente. Tan indispensable como la vivienda y la alimentación resultan ser la

\footnotetext{
${ }^{24}$ Axel Honneth, Foucault und Adorno. Zwei Formen einer Kritik der Moderne (Foucault y Adorno. Dos formas de una crítica de la modernidad), en: Axel Honneth, Die zerrissene Welt des Sozialen. Sozialphilosophische Aufsätze (El mundo desgarrado de lo social. Ensayos filosófico-sociales), Frankfurt: Suhrkamp 1999, pp. 73-92, aquí pp. 84-85.

${ }^{25} \mathrm{Cf}$. Isaiah Berlin, Joseph de Maistre und die Ursprünge des Faschismus (Joseph de Maistre y los orígenes del fascismo), en: Berlin, Das krumme..., op. cit. (nota 15), pp. 123-221.

${ }^{26}$ Alain Finkielkraut, La derrota del pensamiento, Barcelona: Anagrama 1988, p. 111.
} 
familiaridad con los lazos primarios (como el lenguaje y tradiciones histórico-culturales compartidas desde la niñez), la pertenencia a un grupo identificable y distinto de los demás y la comunicación espontánea con parientes y amigos. Sólo una comunidad primaria puede brindar la seguridad emocional y el reconocimiento primordial - exento del principio de rendimiento y desempeño - que evitan las formas extremas de enajenación, soledad, desarraigo y autodesprecio individuales 27 . Los vínculos primarios y el legado de tradiciones vivientes tienen, por lo tanto, funciones positivas para el desarrollo de consciencias individuales sólidas y sin complejos de inferioridad, funciones que no pueden ser reemplazadas por abstracciones como la ética universalista, las obligaciones contractuales, las estructuras burocrático-administrativas y las organizaciones supranacionales, por más importantes y eficaces que éstas también sean.

Por otra parte, los peligros inherentes al particularismo son conocidos y sustanciales. Esta corriente puede exacerbar sentimientos nacionalistas y tendencias irracionalistas; puede contribuir a diluir las grandes contribuciones de la llustración y el racionalismo europeo, a aumentar las discrepancias entre los pueblos, a magnificar las diferencias entre los individuos y a entorpecer el entendimiento entre sociedades y también entre los hombres. Valores particulares, en primera instancia los nacionales, pierden fácilmente su característica de meras señas de identidad, iguales 0 , por lo menos, comparables a las de otras naciones, y se transforman en cualidades sagradas, mejores y más respetables que las de los vecinos y de todos los otros pueblos. Simples peculiaridades identificatorias, sin las cuales no puede vivir ningún individuo y ninguna comunidad, se convierten en evidencias de la propia superioridad sobre los otros, superioridad que debe ser demostrada en los terrenos de la economía, la política y la guerra. La exaltación de lo propio y particular hace olvidar el origen común de todos los grupos humanos, sobre lo cual se basa todo humanismo religioso y secular. Este ensalzamiento particularista permite percibir a cualquier persona y a pueblos enteros como desprovistos de características humanas, es decir como seres inferiores que pueden ser utilizados y hasta asesinados sin remordimientos. Como Isaiah Berlin aseveró, las formas extremas de particularismo terminan en la barbarie ${ }^{28}$.

Aun cuando no existan códigos aceptados universalmente a través del tiempo y el espacio, se puede detectar un mínimo de preceptos recurrentes que constituye algo así como una base común de entendimiento mutuo, sin la cual no habría posibilidad de coexistencia alguna. El asesinato, el robo y la mentira, por ejemplo, aunque siempre

27 Isaiah Berlin, The Counter-Enlightenment, en: Berlin, Against..., op. cit. (nota 14), pp. $10-$ 14.

${ }^{28}$ Isaiah Berlin, Die europäische Einheitundihre Wechselfälle (La unidad europea y sus altibajos), en: Berlin, Das krumme..., op. cit. (nota 15), p. 228. 
han sido practicados extensamente, nunca han recibido una sanción legal o moral positiva. Por otra parte los mortales buscamos habitualmente y en casi todos los contextos geográficos e históricos, como afirmó Isaiah Berlin, el reconocimiento del otro y no el desdén o la incomprensión. Anhelamos igualmente calor humano en lugar del desafecto permanente $y$, sobre todo, deseamos acercarnos a lo que consideramos la verdad y no caer en los lazos del error y el engaño ${ }^{29}$. Consideramos como fundamentales estos principios morales y valores de orientación, no porque hayan sido enunciados por nuestros antepasados con carácter mítico o divino, sino porque creemos ver en ellos la precondición para la convivencia - en un mundo pequeño y común - con otros individuos y otras sociedades. Estos principios conforman la base irrenunciable para que los otros nos reconozcan como humanos y nosotros a ellos. Es decir: no percibimos estos preceptos en cuanto manifestaciones particulares de una sociedad específica y, por ende, como arbitrarias e indiferentes para nosotros, sino como normativas válidas en los contextos más diversos, porque nos ayudan a comprender a los extraños y a convivir con ellos. Su universalidad se deriva, entonces, de una actitud práctico-pragmática que ya ha dado resultados positivos, y no de un fundamento metafísico o teológico. Nos servimos de ellos, dice Isaiah Berlin, cuando resistimos agresiones sociales o cuando nos oponemos a la destrucción de la libertad de parte de regímenes despóticos ${ }^{30}$.

Isaiah Berlin propugnó una síntesis ejemplar para un sentido común guiado críticamente. El racionalismo de la llustración, los derechos individuales, las libertades políticas y la moral universalista deberían combinarse con el pluralismo cultural, el respeto de la identidad de otros pueblos y con el derecho a un desarrollo según parámetros más o menos propios $^{31}$. El resultado sería un liberalismo político incluyente de carácter normativo: de un lado se hallarían las libertades negativas clásicas, dirigidas contra un orden y un Estado con pretensiones autoritarias, libertades aseguradas mediante estatutos legales, y por otro lado se encontrarían las libertades positivas, consagradas a consolidar un orden social que sea, al mismo tiempo, un hogar familiar con el que los ciudadanos puedan identificarse plenamente. Pero: todo lo cual es mucho más fácil de enunciar que de construir en la profana realidad. De todas maneras: tratar de entender lo Otro no significa exculpar sus lados oscuros y menos aún justificarlos.

\section{Los aspectos productivos de la hermenéutica}

\footnotetext{
29 Ibid., pp. 257-258.

30lbid., p. 259.

31Sobre la vida y la obra de Isaiah Berlin cf. Michael Ignatieff, Isaiah Berlin, una vida, Madrid: Taurus / Santillana 1999; Claude J. Galipeau, Isaiah Berlin's Liberalism, Oxford / New York: Oxford U. P. 1994.
} 
La hermenéutica nos enseña que el sujeto cognoscente pertenece inextricablemente al mismo contexto del objeto que quiere conocer 32 . Siguiendo este principio general, las diferentes corrientes de la hermenéutica han realizado una valiosa crítica ala pretensión de objetivismo de la historiografía convencional, de las ciencias sociales y de la metafísica clásica. Han mostrado la insostenibilidad del postulado de soberanía de la autoconciencia que se estudia ella misma ${ }^{33}$. Han criticado el ideal de la objetividad aseverando la unidad entre el pensamiento y el habla. No puede haber, entonces, un pensar que esté libre de una cierta perspectiva. Toda interpretación, según Hans-Georg Gadamer, conlleva un momento de auto-interpretación ${ }^{34}$. Las humanidades y ciencias espirituales, de acuerdo a este autor, no pueden ser subsumidas al ideal sistemático de un saber estrictamente metódico. Todo acto de entender tiene un elemento indispensable de precomprensión, del cual el investigador (también el filósofo, el intérprete) no se puede eximir ${ }^{35}$. Todo prejuicio resulta verdadero y coherente, porque toda comprensión es fundamentalmente individual. Gadamer distingue, sin embargo, los prejuicios verdaderos de los falsos ${ }^{36}$. Estos últimos nos llevan a la incomprensión.

Por otra parte, el concepto de autoridad, nos dice Gadamer, tiene que ver con conocimiento y no con obediencia. Hay que corregir, por lo tanto, el prejuicio de la llustración contra los prejuicios, hay que desarrollar una ciencia de los prejuicios que sea justa con el sentido productivo de los prejuicios que subyacen a todo juicio, sin hacer peligrar el sentido de la crítica a todos los prejuicios que amenazan el conocimiento. La hermenéutica, asevera Gadamer, está más interesada en preguntas que en respuestas, puesto que el único camino para entender un enunciado es encontrar la pregunta desde la cual el enunciado es una respuesta ${ }^{37}$.

32 Hans-Georg Gadamer, Einführung (Introducción), en: Hans-Georg Gadamer / Gottfried Boehm (comps.), Seminar: Philosophische Hermeneutik (Seminario: hermenéutica filosófica), Frankfurt: Suhrkamp 1976, pp. 7-40.

33 Postulado compartido claramente por Jürgen Habermas, Analytische Wissenschaftstheorie und Dialektik. Ein Nachtrag zur Kontroverse zwischen Popper und Adorno (La teoría analítica de la ciencia y la dialéctica. Un suplemento a la controversia entre Popper y Adorno), en: Theodor W. Adorno et al., Der Positivismusstreit in der deutschen Soziologie (La disputa del positivismo en la sociología alemana), Neuwied / Berlin: Luchterhand 1969, p. 156.

34Hans-Georg Gadamer, Die philosophischen Grundlagen des 20. Jahrhunderts (Los fundamentos filosóficos del siglo XX), en: Hans-Georg Gadamer / Gottfried Boehm (comps.), op. cit. (nota 32), pp. 316-326.

35 Para lo siguiente: Hans-Georg Gadamer, Wahrheit und Methode. Grundzüge einer philosophischen Hermeneutik (Verdad y método. Fundamentos de una hermenéutica filosófica), Tübingen: Mohr-Siebeck 1975, pp. 290-295.

36lbid., pp. 298-306.

37Hans-Georg Gadamer, VernunftimZeitalter der Wissenschaft (La razón en la era de la ciencia), Frankfurt: Suhrkamp 1976, p. 101. 
Hay que rescatar teóricamente las influencias del pasado en y para el presente 38 .

Todo esto tiene que ver, en el fondo, con una diferenciación más antigua que había sido establecida por Johann Gustav Droysen 39 y Wilhelm Dilthey40: la historia y las ciencias sociales estudian habitualmente asuntos específicos, particulares e irrepetibles, a los cuales no se les puede aplicar las leyes científicas que explican fenómenos basadas en la causalidad y la regularidad. En las ciencias sociales y humanas habría que proceder tratando de comprender los motivos y las razones de cada objeto de análisis, lo que abre un gran campo a la exégesis. Esta relativa flexibilidad de la interpretación es muy importante metodológicamente. La hermenéutica analógica, en la versión de Mauricio Beuchot41, nos ayuda, por ejemplo, a encontrar perspectivas intermedias valiosas entre el escepticismo doctrinario y la seguridad dogmática; entre la concepción clásica de la llustración europea y la negación deconstruccionista del racionalismo; entre la doctrina que postula la existencia de leyes obligatorias de la historia y aquella que niega esos decursos forzosos de la evolución; entre la concepción que afirma el sentido pleno de la evolución histórica y el enfoque que proclama el sinsentido primordial de ese mismo desarrollo; y asimismo entre univocismo y equivocismo. Beuchot asevera que

"[...] una hermenéutica analógica intenta abrir el campo de validez de interpretaciones cerrado por el univocismo, pero también cerrar y poner límites al campo de validez abierto desmesuradamente por el equivocismo, de modo que pueda haber no una única interpretación válida, sino un pequeño grupo de interpretaciones válidas. [...] Creemos que puede darse un tipo de interpretación que sea preponderantemente abierto y, sin embargo, aspire a lograr cierta unidad" 42.

Aquí hay que mencionar la crítica de Jürgen Habermas a Gadamer. Si la comprensión del sentido fuera totalmente dependiente del contexto, esto nos llevaría a sobreestimar la precomprensión contextualizada de todo hecho y de toda teoría, a sobreestimar una sucesión infinita de

\footnotetext{
38Sobre esta temática cf. Udo Tietz, Hans-Georg Gadamer zur Einführung (Introducción a Gadamer), Hamburgo: Junius 2000, pp. 37-45, 76.

39 Johann Gustav Droysen, Die Interpretation (La interpretación), en: Hans-Georg Gadamer / Gottfried Boehm (comps.), op. cit. (nota 32), pp. 182-186, especialmente p. 182.
}

40 Wilhelm Dilthey, Entwürfezur Kritik der historischen Vernunft (Esbozos para una crítica de la razón histórica) en: Hans-Georg Gadamer / Gottfried Boehm (comps.), op. cit. (nota 32), pp. 189-220, especialmente p. 196.

41 Mauricio Beuchot, La racionalidad analógico-simbólica como propuesta para la post-modernidad, en: ANALOGÍA FILOSÓFICA (México), vol. XV (2001), Nº 2, pp. 205217.

${ }^{42}$ Mauricio Beuchot, Tratado de hermenéutica analógica. Hacia un nuevo modelo de interpretación, México: UNAM / Ítaca 2000, p. 11. Cf. también: Mauricio Beuchot, Hermenéutica, analogía y símbolo, México: Herder 2004. 
preconocimientos (presupuestos, prejuicios, pre-entendimientos) en cadena interminable $y$, por ende, a sobreestimar la tradición oral $o$ literaria como el único camino del conocimiento. Gadamer, según Habermas, habría insistido, con razón, en la rehabilitación correcta del prejuicio como instrumento cognitivo, pero la posición dogmatizada de Gadamer lleva al enaltecimiento desmedido de la cadena tradicional de teorías y prejuicios, lo que resultaría una exageración 43 , pues conduce a una ontologización del idioma, a una rehabilitación del prejuicio como tal y a una devaluación de la "fuerza de la reflexión"44. Habermas afirma que la apropiación de la tradición debe ser reflexionada, razonada, criticada, analizada. Si bien es cierto que no existe ninguna razón eximida de algún contexto socio-histórico, tampoco se puede aseverar que todos los criterios de la razón se modifican con cada nuevo contexto ${ }^{45}$. No hay duda, dice Habermas, de que toda comprensión presupone y conlleva una conformidad, un consentimiento básico, pero este consentimiento no siempre resulta ser racional o simplemente confiable - en realidad raravez lo es 46 -, pues, como asevera Habermas, el idioma no es sólo una expresión de conformidad y consentimiento, sino también una expresión de poder y dominio social. El idioma puede contener un elemento ideológico como legitimación de relaciones de violencia organizada. Hay que cuestionar la idealización de la lengua que realizan los postmodernistas en la sucesión de Martin Heidegger y, por ende, hay que limitar la pretensión universal de la hermenéutica. La crítica de las ideologías debería tomar el lugar de la hermenéutica. Esta última se revelaría como una pseudo-comunicación, como una conversación inofensiva entre filósofos sobre la base de la perpetuación del status quo teórico-filosófico del instante ${ }^{47}$.Efectivamente: la teoría de Gadamer tiende a debilitar la reflexión racional y a identificar cualquier consenso lingüístico momentáneo con un consenso genuinamente racional. La

\footnotetext{
43 Jürgen Habermas, Zur Logik der Sozialwisschenschaften (Sobre la lógica de las ciencias sociales), Frankfurt: Suhrkamp 1985, p. 359; cf. también Udo Tietz, op. cit. (nota 38), pp. 74, 121-125.

44 Jürgen Habermas, Zur Logik..., op. cit. (nota 43), p. 303.- Sobre este punto cf. Udo Tietz, op. cit. (nota 38), p. 124.

45 Jürgen Habermas, Der philosophische Diskurs der Moderne. Zwölf Vorlesungen (El discurso filosófico de la modernidad. Doce lecciones), Frankfurt: Suhrkamp 1985, p. 220

46 En la obra de Karl Marx nos encontramos con prejuicios no productivos y más bien irracionales, como (1) la vieja tradición germánica anti-eslava no criticada y (2) una justificación de relaciones fácticas de poder en nombre de una presunta racionalidad histórica superior. Son prejuicios "falsos" (en la terminología de Gadamer) que nos conducen a la incomprensión del Otro. Cf. los ejemplos contenidos en la nota 20 de este ensayo.- En este contexto Hannah Arendt aseveró que no podemos regresar a las teorías marxistas en todas sus variantes, las cuales, pese a toda su riqueza conceptual, desatienden la pluralidad de los proyectos humanos y desaprueban la diversidad de los programas sociopolíticos. Cf. Hannah Arendt, Was ist Politik? (¿Qué es la política?), edición de Ursula Ludz, Munich: Piper 2010, pp. 9, 28, 96-98.

47 Jürgen Habermas, Zur Logik..., op. cit. (nota 43), p. 309.
} 
hermenéutica gadameriana fomenta en la praxis una identificación de tradición con razón.

Paralelamente al enaltecimiento de la hermenéutica, nos dice Habermas, Gadamer habría propiciado una "magnífica recuperación de la tradición humanista"48, basada en la herencia del espíritu libre, es decir: racionalista y consciente de su libertad49. Esta recuperación se manifiesta también en su hermoso ensayo sobre el arte como juego y símbolo, donde Gadamer, pese a su crítica severa de las concepciones idealistas y tradicionalistas acerca de la belleza artística ${ }^{50}$, afirma - de manera muy clásica - que las grandes obras de arte generan un "incremento del ser" 51, una participación en la eternidad 52 y una garantía de que lo verdadero no es inalcanzable pese a la presencia perenne de imperfecciones, maldades y confusiones fatales ${ }^{53}$.En la propia terminología de Gadamer: la "función ontológica" 54 de lo bello es ayudar a cerrar el abismo entre lo ideal y lo real, una función que se aviene mal con un relativismo dogmático referido a la estética.

También hay que mencionar la crítica radical de Jacques Derrida 55 a Gadamer. Desde la óptica deconstructivista toda comprensión es un conocimiento equivocado, un malentendido. Gadamer creía que toda comprensión puede ser un malentendido, pero también una comprensión diferente. Para los postmodernistas radicales, sin embargo, todo intento de entendimiento y significación termina necesariamente en una crisis cognoscitiva. Por su parte Gianni Vattimo aseveró que la hermenéutica, en el sentido más radical - como aparece en las obras de Nietzsche y Heidegger -, representaría paradójicamente el desarrollo y la madurez del mensaje cristiano56. Para redondear este acápite hay que recordar la crítica de Georg Stein era la hermenéutica en general y al postmodernismo francés en particular: estas corrientes de pensamiento tendrían una inclinación a "la jerga opaca" y a "la casi litúrgica falta de

\footnotetext{
${ }^{48}$ Jürgen Habermas, Hans-Georg Gadamer. Urbanisierung der Heideggerschen Provinz (Hans-Georg Gadamer. La urbanización de la provincia heideggeriana), en: Jürgen Habermas, Philosophisch-politische Profile (Perfiles filosófico-políticos), Frankfurt: Suhrkamp 1998, pp. 392-401, aquí p. 400.

49 bid., p. 401.

50 Hans-Georg Gadamer, Die Aktualität des Schönen. KunstalsSpiel, Symbol und Fest(La actualidad de lo bello. El arte como juego, símbolo y fiesta), Stuttgart: Reclam 1977, pp. 18-27, 43, 53.

51 Ibid., p. 47.

52 lbid., p. 60.

53 lbid., p. 20, 42.

54 Ibid., p. 20.

55 Jacques Derrida, Grammatologie (Gramatología), Frankfurt: Suhrkamp 1983, pp. 105-107.- Sobre esta temática cf. Udo Tietz, op. cit. (nota 38), pp. 141-147.

56 Gianni Vattimo, Das Zeitalter der Interpretation (La era de la interpretación), en: Richard Rorty / Gianni Vattimo, Die Zukunft der Religion (El futuro de la religión), compilación de Santiago Zabala, Frankfurt: Suhrkamp 2006, pp. 49-63, aquí 53-54.
} 
aliento"57. Esta decadencia estilística encubre algo mucho más grave. Steiner señala que nuestra era, la de la irreverencia universal e inescapable, del "escepticismo obligatorio de las ciencias", prescribe dogmáticamente "la nivelación por abajo"58. A esto conduce, en última instancia, el postulado de que la tradición conformada por los prejuicios es el mejor camino del conocimiento científico e intelectual. Para el campo de la prosaica praxis cotidiana esto significa, de acuerdo a Steiner, que "[...] nuestros ídolos tienen que exhibir cabeza de barro. Cuando se eleva el incienso lo hace ante atletas, estrellas del pop, los locos del dinero o los reyes del crimen"59. Esto conlleva la pérdida de la calidad intelectual o artística - el reino de la mediocridad - que está asociada necesariamente a la aceptación de los prejuicios como vía del conocimiento, por más filtros de calidad que se instalen en este procedimiento.

\section{Contra el pesimismo dogmático: los derechos humanos como base del despliegue de las diferencias}

Las varias alusiones positivas a la obra de Jürgen Habermas no significan una adopción acrítica de sus ideas. Habermas acierta con acostumbrada brillantez en su tratamiento ideológico-crítico del discurso postmodernista, poniendo en evidencia todos sus lados flacos y en relieve los aspectos rescatables del racionalismo y la llustración. El conjunto de su obra denota, sin embargo, una cierta ceguera frente a los grandes problemas de la actualidad - la crisis del medio ambiente, el colapso del socialismo y del Estado de bienestar social, el eurocentrismo y el antropocentrismo de los magnos sistemas teóricos, la decadencia de la estética pública en todos los regímenes dominados por la civilización industrial -, problemas que no fueron ni anticipados ni analizados adecuadamente por Habermas. En sus escritos, por ejemplo, se buscaría vanamente una sola mención a las deformaciones burocráticas o al hastío de la vida generados por la tutela omnipotente del Estado benefactor en los países influidos por la socialdemocracia escandinava o regímenes similares 60 . Habermas concibió una defensa muy convencional y poco convincente del Estado de bienestar social encarnado en los regímenes de la socialdemocracia $y$, en general, del socialismo en cuanto modelo de organización social, definiendo a este último en términos de extraordinaria modestia: socialismo sería aquel sistema de cuño falibilista, que corrige sus propios errores y que trata de disminuir la represión evitable y la injusticia identificable y que intenta impedir la erosión de formas solidarias de vida

${ }^{57}$ George Steiner, Lecciones de los maestros, México: FCE / Sirvela 2007, p. 80. 58 Ibid., p. 172.

$59 /$ bid.

${ }^{60} \mathrm{Cf}$. como contraste el brillante ensayo de Hans Magnus Enzensberger, Ach Europa (Ay Europa), Frankfurt: Suhrkamp 1987, pp. 9-49. 
social61. Muy similar resulta ser la sociedad emancipada vislumbrada por Adorno cuando este autor desciende excepcionalmente a una descripción materialista-concreta de la misma62.

Max Horkheimer(1895-1973) y Theodor W. Adorno(1903-1969), pese a la sutileza y originalidad de su análisis de la llustración, han exagerado probablemente la corruptibilidad del conocimiento, han conectado inextricablemente el conocimiento con la culpabilidad y han terminado identificando la razón instrumental con la razón en sentido global63. La consecuencia es el pesimismo histórico extremo y el "escepticismo desenfrenado" de ambos autores. Lo deplorable, como lo señaló Habermas, es que Adorno y Horkheimer analizaron todos los recovecos y laberintos de la razón en su marcha hacia el desastre y la inhumanidad, y lo hicieron heroica y detenidamente, sin claudicar y exigiendo al lector un genuino sacrificio, pero se entregaron mansamente a la dinámica autodestructiva de la razón, diagnosticada críticamente por ellos, y no cuestionaron seriamente las causas de ese pesimismo dogmático64. En este punto se puede consignar una contradicción performativa en el pensamiento de Adorno y Horkheimer: si la razón se ha convertido toda ella en totalitaria e instrumental, entonces no se la puede censurar fehacientemente desde ninguna perspectiva, y los textos de estos autores caerían bajo la clasificación de meros ejercicios de una racionalidad instrumental. Pero la existencia misma de la Teoría Crítica de la Escuela de Frankfurt constituye un alegato en el sentido de que es posible y recomendable una posición que supere el relativismo axiológico, que logre una visión realmente crítica de la totalidad social y que, aunque sea muy precariamente, señale el derrotero de una praxis razonable. En un punto concreto habríaque defender, por ejemplo, la vieja - ¿̇por qué

61 Jürgen Habermas, Die Neve Unübersichtlichkeit (El nuevo desorden), Frankfurt: Suhrkamp 1985, especialmente p. 42, p. 73, 152. Sobre - Cf. también: David Sobrevilla, El problema de la modernidad: el debate entre Lyotard y Habermas, en: SOCIALISMO Y PARTICIPACION (Lima), № 43, septiembre de 1988, pp. 65-82.

${ }^{62}$ Gerhard Schweppenhäuser, op. cit. (nota 2), pp. 100-101.

63 Cf. dos excelentes ensayos: ÉtienneBarilier, Gegen den neven Obskurantismus (Contra el nuevo oscurantismo), Frankfurt: Suhrkamp 1999, pp. 131-132; Thomas Rentsch, Vermittlungals permanente Negativität. Der Wahrheitsanspruch der "Negativen Dialektik" auf der Folie von Adornos Hegelkritik (La mediación como negatividad permanente. La pretensión de verdad de la "Dialéctica negativa" con el trasfondo de la crítica de Adorno a Hegel), en: Christoph Menke / Martin Seel (comps.), op. cit. (nota 8), pp. 84-102, especialmente pp. 96-97.

64Jürgen Habermas, Der philosophische Diskurs..., op. cit. (nota 45), p. 137, 156.- Sobre la contradición performativa de Adorno y Horkheimer y en torno a la diferencia entre las diversas generaciones de la Escuela de Frankfurt cf. dos brillantes ensayos: Martin Jay, The Debate o ver Performative Contradiction: Habermas vs. the Post-Structuralists, en: Axel Honneth et al. (comps.), Zwischenbetrachtungen. Im Prozess der Aufklärung (Consideraciones provisorias. En el proceso del esclarecimiento), Frankfurt: Suhrkamp 1989, pp. 171-209; Helmut Dubiel, Herrschaft oder Emanzipation? Der Streitum die Erbschaft der kritischen Theorie (¿̇Dominio o emancipación? La pugna en torno al legado de la teoría crítica), en: ibid., pp. 504-518. 
vieja? - concepción universitaria humboldtianaen torno al poder formativo de la ciencia y la educación contra su destrucción postmodernista o su devaluación tecnocrática, como lo postulaReinhardMehring 65 , en lugar de diluir toda idea de que Estado representa también la normativa de la justicia, fomentando doctrinas sobre el belicismo aparentemente fundamental y irrenunciable de los seres humanos, concepción popularizada por Carl Schmitt, que, en el fondo se asemeja a la concepción original de Horkheimer y Adornob6.

Por otra parte, es importante indicar que la actual corriente fuertemente adversa a cualquier universalismo (la "tiranía de lo general", según JeanFrançois Lyotard 67 ) parte de una equivocación liminar: confundir universalidad con uniformidad $\mathrm{o}$, política y concretamente, la validez de principios de derecho general con un impulso de aplastar las diferencias sociales y culturales. Precisamente porque las condiciones del surgimiento de regímenes, instituciones, normas y costumbres son contingentes y aleatorias, se requiere de un estatuto, aceptado generalmente, que garantice la coexistencia de lo diverso. La legitimidad de los derechos humanos no está determinada por su lugar de origen ni limitada por la sociedad donde fueron enunciados por vez primera. Estos derechos no impiden de ninguna manera que cada individuo despliegue su potencialidad de desarrollo $y$, sobre todo, sus peculiaridades y singularidades en el marco de culturas muy diversas entre sí. La razón de ello reside en el hecho de que los derechos humanos no prescriben obligatoriamente cual es el contenido específico de ese desarrollo potencial, ni cual deberá ser la configuración definitiva de aquellas peculiaridades y ni siquiera cual podría ser la definición sustancial de una humanidad bien lograda. Los derechos humanos constituyen sólo la base

\footnotetext{
${ }^{65}$ Reinhard Mehring, Politische Philosophie (Filosofía política), Leipzig: Reclam 2005, p. 93 , 111.

66Ellen Kennedy, Carl Schmitt und die "Frankfurter Schule". Deutsche Liberalismuskritikim 20. Jahrhundert (Carl Schmitt y la "Escuela de Frankfurt". La crítica alemana del liberalismo en el siglo XX), en: GESCHICHTE UND GESELLSCHAFT (Göttingen / Berlín), vol. 12 (1986), № 3, pp. 380-419, especialmente pp. 388-391; Helmut Dubiel, Kritische Theorie der Gesellschaft. Eine einführende Rekonstruktion von den Anfängen im Horkheimer-Kreis bis Habermas (Teoría crítica de la sociedad. Una reconstrucción introductoria desde los comienzos en el círculo de Horkheimer hasta Habermas), Weinheim: Juventa 1988, pp. 92-94.

67 Cf. los instructivos ensayos: Jutta Georg-Laver, Das "postmoderne Wissen" und die Dissens-Theorie von Jean-François Lyotard (El "saber postmoderno" y la teoría del disenso de Jean-François Lyotard), en: Peter Kemper (comp.), "Postmoderne" oder Der Kampfum die Zukunft. Die Kontroverse in Wissenschaft, Kunstund Gesellschaft ("La postmodernidad" o la lucha por el futuro. La controversia en ciencias, artes y sociedad), Frankfurt: Fischer 1988, pp. 189-206; Wolfgang Welsch, "Postmoderne". Genealogie und Bedeutung eines umstrittenen Begriffs ("Postmodernidad". Genealogía y significado de un concepto controvertido), en: ibid., pp. 9-36, especialmente pp. 26-29; Josep Picó (comp.), Modernidad y postmodernidad, Madrid: Alianza 1988.
} 
(pero la base indispensable) para que el Hombre pueda desenvolverse de acuerdo a sus propios cánones. Justamente para este fin los derechos le protegen, por ejemplo, de las muy probables arremetidas de sus congéneres, de los inevitables ataques de otros grupos organizados y de las insidiosas agresiones del aparato estatal, fenómenos todos muy habituales en el Tercer Mundo, que para muchos cientistas sociales representa todavía el reino de la diversidad. Los derechos humanos de corte universalista fundan las condiciones posibilitantes para el desenvolvimiento práctico-realista de casi todo particularismo en un mundo complejo y altamente interrelacionado como el contemporáneo. La facultad de ejercer uno mismo violencia es permutada por el interés de no ser víctima de la violencia ajena. Esta renuncia a la violencia constituye una reciprocidad negativa: el desistir por ambos lados a matarse, a robarse y a perjudicarse por razones religiosas o políticas, es lo que dio lugar posteriormente a los derechos a la vida y a la integridad física, a la propiedad y a la libre expresión. Independientemente de lo que cada persona considere imprescindible para la realización de su singularidad, para ello tiene que partir necesariamente de la seguridad de su integridad física: el derecho a la vida es el primero de los grandes estatutos ético-legales de índole universalista.

Finalmente se puede acudir al testimonio de una gran pensadora contemporánea, Martha C. Nussbaum. Ella afirma que las diferencias culturales que celebran los relativistas emergen como momentos constituyentes de una identidad colectiva propia e inconfundible sólo en medio de comunidades aisladas y con bajos niveles educativos. Cuando se dispone de más información, la gente de los estratos bajos adquiere espontáneamente ideas e imágenes sobre su propia dignidad humana que tienden a asemejarse a los principios universalistas del racionalismo68, a los que pertenecen algunas de las corrientes de la tradición occidental, plural y variada como casi todos los legados culturales.

\footnotetext{
${ }^{68}$ Martha C. Nussbaum, Menschliches Tun und soziale Gerechtigkeit. ZurVerteidigung des aristotelischenEssentialismus (La acción humana y la justicia social. Una defensa del esencialismo aristotélico), en: HolmerSteinfath (comp.), WasisteingutesLeben? Philosophische Reflexionen (¿̇Qué es una buena vida? Reflexiones filosóficas), Frankfurt: Suhrkamp 1998, pp. 196-234, especialmente pp. 201-202, 229-234.
} 